\title{
Five Serum Trace Elements Associated with Risk of Cardia and Noncardia Gastric Cancer in a Matched Case-Control Study
}

This article was published in the following Dove Press journal: Cancer Management and Research

\author{
Yulan Lin (D) \\ Chuancheng Wu (iD ${ }^{2,3}$ \\ Wei Yan $^{4}$ \\ Saixiong Guo ${ }^{4}$ \\ Baoying Liu ${ }^{2,3}$ \\ 'Department of Epidemiology and Health \\ Statistics, School of Public Health, Fujian \\ Medical University, Fuzhou 350I22, \\ Fujian, People's Republic of China; \\ ${ }^{2}$ Department of Preventive Medicine, \\ School of Public Health, Fujian Medical \\ University, Fuzhou, Fujian, People's \\ Republic of China; ${ }^{3}$ Fujian Provincial Key \\ Laboratory of Environment Factors and \\ Cancer, Fujian Medical University, \\ Fuzhou, People's Republic of China; \\ ${ }^{4}$ Fujian Xianyou County Hospital, Putian, \\ People's Republic of China
}

Correspondence: Chuancheng Wu; Yulan Lin

Email 78926674@qq.com;

yulanlin@fjmu.edu.cn
Background: Serum trace elements have for some time been suggested to influence the development of gastric cancer, but evidence is still lacking.

Methods: All newly diagnosed patients with gastric cancer were compared with healthy controls 1:1 matched by sex, age ( \pm 3 years), and place of residence during 2013-2015. The serum concentration of all trace elements was analyzed using inductively coupled plasma mass spectrometry. Heliobacter pylori infections in cases were diagnosed using the rapid urease test, while in controls were detected using the colloidal gold method.

Results: A total of 122 cases of gastric cardia cancer (GCC) and 177 gastric noncardia cancer (NCGC), and 299 matched healthy controls were included. Positive associations were found between serum copper and copper/zinc ratio and risk of overall gastric cancer $\left(\mathrm{OR}_{4 \text { th vs }}\right.$

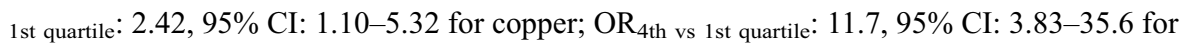
copper/zinc ratio), and for both GCC and NCGC subtypes. Serum selenium was inversely associated with the risk of NCGC $\left(\mathrm{OR}_{4 \text { th }}\right.$ vs 1 st quartile: $\left.0.18,95 \% \mathrm{CI}: 0.07-0.51\right)$, while molybdenum seems to reduce the risk of $\mathrm{GCC}\left(\mathrm{OR}_{4 \text { th }}\right.$ vs 1 st quartile: $\left.0.12,95 \% \mathrm{CI}: 0.03-0.47\right)$. Strong inverse associations were also detected between serum calcium and risk of all groups of gastric cancer (all $p$ for trend $<0.05$ ).

Conclusion: The current study indicated statistically significant positive associations between serum copper, copper/zinc ratio, and gastric cancer, as well as inverse associations among selenium, molybdenum, and calcium. The results shall be carefully interpreted before further in vivo animal studies show definitive evidence.

Keywords: gastric cancer, serum trace elements, nutrition, environment

\section{Introduction}

Although the incidence has been decreasing in the past decades, gastric cancer remains globally the third most frequent cause of death from cancer. Incidence varies greatly among populations and is higher in Asian and Central and South American countries but lower in North America and Western Europe. ${ }^{1}$ Migration studies found lower incidence of gastric cancer among immigrants moved from high-risk regions to lowrisk regions, which indicated that environmental exposures, such as food, could play an important role in the development of this disease. ${ }^{2,3}$ Furthermore, higher incidences of gastric cancer were usually found in those regions with more infertile lands, high mountains, or excessive heavy metals levels in soil, cereals, and drinking water. A previous study confirmed that this environmental pollution by trace elements might contribute partly to their high incidence of gastric cancer. ${ }^{4}$ 
Some early studies have investigated the role of trace elements in the development of gastric cancer, but the results were inconsistent and the mechanisms of the effect of trace metals on gastric cancer are still far from being elucidated completely. Copper $(\mathrm{Cu})$, zinc $(\mathrm{Zn})$, selenium $(\mathrm{Se})$, iron $(\mathrm{Fe})$, molybdenum $(\mathrm{Mo})$, magnesium $(\mathrm{Mg})$, and calcium (Ca) are essential trace metals and components of critical enzyme systems, playing key roles in maintaining DNA integrity by preventing oxidative DNA damage or affecting gene mutation. ${ }^{5-7}$ The main sources of these trace elements are food and drinking water. The variations in these mineral levels were related to the incidence of several cancers. For example, Se has been studied for antioxidant and anticancer properties, ${ }^{8,9}$ especially against gastric cancer. ${ }^{10}$ Inverse associations were also obtained between serum $\mathrm{Zn}$ and risk of gastric cancer in some early studies. ${ }^{11,12}$ A higher level of $\mathrm{Cu}$ alone was also found significantly higher in cancerous human stomach compared to normal samples. ${ }^{13}$ More importantly, $\mathrm{Zn}$ and $\mathrm{Cu}$ are known as key cofactors in several enzymes, which include $\mathrm{Cu} / \mathrm{Zn}$ superoxide dismutases (SODs) decomposing superoxide radicals to $\mathrm{H}_{2} \mathrm{O}_{2}$ and playing a significant role against oxidant stress in several DNA repair proteins.${ }^{14,15}$ Surprisingly, a previous study has demonstrated that high serum levels of $\mathrm{Cu} / \mathrm{Zn}$ superoxide dismutase can be related to an increased gastric cancer risk. ${ }^{16}$ The association between $\mathrm{Cu} / \mathrm{Zn}$ ratio and risk of gastric cancer is largely unknown and therefore needs further investigation. Although it seems biologically plausible for $\mathrm{Fe}$ to be associated with gastric carcinogenesis, the evidence is rather heterogeneous and insufficient to lead to any conclusions. ${ }^{17}$

Xianyou County in Putian City is located between east longitude $118^{\circ} 27^{\prime}-118^{\circ} 56^{\prime}$ and north latitude $25^{\circ} 11^{\prime}-25^{\circ}$ $43^{\prime}$ on the southeast coast of Fujian province, China, and had an estimated population of 2.1 million in 2012. In this county, gastric cancer was the dominant leading cause of death, explaining $30.43 \%$ of total cancer death. ${ }^{18}$ The standardized mortality rate of gastric cancer was $49.47 /$ 100,000 in Xianyou County, which was 2.23-fold higher than the Chinese national average $(21.9 / 100,000) .{ }^{18}$ Mountain areas were observed to have the highest mortality rate $(94.4 / 100,000)$, in comparison to the lowest rate observed in coastal regions $(26.4 / 100,000)$ (data not shown). In line with this finding, an earlier study also confirmed a lower serum level of $\mathrm{Zn}$ and a higher level of $\mathrm{Cu} / \mathrm{Zn}$ ratio in the healthy population in Putian City compared to that of other regions in Fujian province with lower incidence of gastric cancer. ${ }^{19}$ This evidence indicates that trace element variations might play a critical role in the development of gastric cancer in this area. However, to date, no large-scale epidemiological studies have proved the association. Thus, the aim of this study was to investigate whether serum concentrations of trace elements are associated with gastric cancer risk, thus to explain partly the high incidence of gastric cancer in Xianyou County.

\section{Materials and Methods Study Design and Population}

A population-based case-control study was conducted in Xianyou County between March 2013 and December 2015. All newly diagnosed cases of gastric cancer in Xianyou County Hospital were identified. The case identification was performed by clinical research nurses recruited and trained specifically for the study. All individuals who were aged $\geq 18$ years and have lived in Xianyou for at least 10 years were eligible and recruited in Xianyou County Hospital. Gastric cancer was defined according to the International Classification of Diseases, 10th Revision (ICD-10) code, and was subclassified as gastric cardia cancer (GCC) if it involved the esophagogastric junction and as noncardia gastric cancer (NCGC) if it did not. Patients who have started cancer treatment, had a history of any cancer, have mental illness, and are diagnosed with diabetes and those unable to complete the questionnaire were excluded. Controls were individually matched (1:1) to cases based on sex, age ( \pm 3 years), and place of residence. They were required to live in the same town or a town with a similar incidence of gastric cancer, and were required to be living in Xianyou County for at least 10 years with no prior history of gastric cancer. The study was approved by the ethics committees at Fujian Medical University. Written consents were obtained from all participants at study enrollment.

\section{Questionnaire Data Collection}

All participants were personally face-to-face interviewed by trained research nurses from Xianyou County Hospital. A structured and standard questionnaire consisting of 337 items under 8 categories was used for the data collection. The questionnaires included the following categories: (i) demographic factors (16 items), including the subject's age, height, weight, marital status, education level, monthly income, etc.; (ii) occupational history (17 items), including profession, pesticide exposure at work, etc.; (iii) lifestyles 
(70 items), including smoking habits, use of alcohol, tea consumption, etc.; (iv) dietary intake (140 items); (v) personal medical history (33 items), including personal disease records, medication, etc.; (vi) family cancer history (18 items), including family history (first and second-degree relatives) of any cancer, gastric cancer, and esophageal cancer; (vii) mental health (9 items); and (viii) cancerrelated diagnoses and treatment (34 items), including surgery, chemotherapy, and radiotherapy, etc. Smoking habit was defined as consuming at least one cigarette per day during the last 6 months or longer.

\section{Blood Sampling}

Fasting blood samples were collected from all study participants in the morning in Xianyou County Hospital. Approximately $5 \mathrm{~mL}$ of venous blood was collected with ethylenediaminetetraacetic acid (EDTA) as an anticoagulant for erythrocyte preparation and serum. EDTA tubes were centrifuged for $10 \mathrm{~min}$ at $3000 \mathrm{rpm}$, and the serum sample was separated and kept in trace element-free tubes and stored at $-80{ }^{\circ} \mathrm{C}$ prior to analyses.

\section{Detection of the Concentrations of 7 Trace Elements}

The serum concentration of all trace elements was analyzed using inductively coupled plasma mass spectrometry (ICP-MS; Perkin Elmer NexION 350X, USA). The ICPMS minimal detection cut-off was $0.5 \mathrm{ng} / \mathrm{L}$. Deionized water (18.2 M $\Omega . c m)$, which was gained from a Milli-Q water purification system (Millipore Co., USA), was used throughout the experiment. Up-s grade (ultrapure) nitric acid $\left(\mathrm{HNO}_{3}\right)$ was purchased from Suzhou Crystal Clear Chemical Corporation (Suzhou, China). Internal standard solution (100 $\mu \mathrm{g} / \mathrm{mL})$ (PE\#: N9400381) was purchased from Perkin Elmer Life and Analytical Sciences (Shelton, CT, USA).

The preparation of serum samples before ICP-MS analysis followed the standard procedure of microwave digestion methodology (Supplemental Table 1). For quality control, we conducted an additional recovery test to monitor measurement accuracy, and also parallel tests to check the precision among randomly selected samples. For the recovery test, each serum sample was divided in half, one of which was analyzed with the mixed serum sample. The recovery rate ranged between $95.18 \%$ and $109.24 \%$ (Supplemental Table 2). To test the precision of measurement, each selected serum sample was divided into 5 small samples, and 5 parallel tests were performed under the same experimental conditions. The relative standard deviations measured among 7 elements ranged from $0.56 \%$ to $9.71 \%$.

\section{Measurement of Heliobacter pylori Infection}

All GC cases underwent gastroscopy in Xianyou County Hospital, and $H$. pylori infections for these cases were diagnosed using the rapid urease test (RUT). ${ }^{20}$ Meanwhile, H. pylori infection for controls was detected using the colloidal gold method through identifying urease in a blood sample. ${ }^{21}$ The colloidal gold method is a simple and noninvasive approach, which has been widely evaluated with high accuracy compared to traditional tools. ${ }^{21}$ In a recent Chinese multicenter study evaluating $H$. pylori infections for 378 participants, the sensitivity, specificity, positive predictive value, negative predictive value, and concordance rate of the colloidal gold method were $84.4 \%$, $92.6 \%, 96.0 \%, 73.7 \%$, and $87.0 \%$, respectively, in comparison to the "gold standard" ${ }^{13} \mathrm{C}$ urea breath test (UBT). ${ }^{22}$

The procedure of the colloidal gold method has been described in an earlier study. ${ }^{22}$ In brief, 2-3 drops of blood were mixed with sample diluent, and the results were evaluated within 5-8 minutes by reading red color bands. The presence of 2 red color bands (" $T$ " band and " $C$ " band, ie, testing band and control band) within the result window indicated a positive result. The presence of only 1 color band indicated a negative result. All assessment kits were purchased from Shanghai Kaichuang Biotechnology Co., Ltd from Shanghai, China.

\section{Statistical Analysis}

Since most of the serum concentrations of trace elements were not normally distributed, we used the median and interquartile range to describe the distributions. The $T$-test (normally distributed) and Wilcoxon rank-sum test (nonnormally distributed) were used for the comparisons of continuous variables. To assess the effect of trace elements on the risk of gastric cancer, conditional logistic regression was used to estimate adjusted odds ratios (ORs) and their 95\% confidence intervals (CIs). Serum concentrations of trace elements were classified into quartiles based on levels of controls. We adjusted for potential confounding factors including age group ( $<55,55-64,65-74, \geq 75$ years), sex (male, female), body mass index (BMI; <18,5, 18.5-24.9, 
$\geq 25 \mathrm{~kg} / \mathrm{m}^{2}$ ), education level ( $\leq 7,7-9, \geq 10$ years), occupation (farmer, industrial worker, office worker, others), household income $(<600,600-1000, \geq 1000$ Chinese Yuan/month/person), smoking (yes, no), chronic atrophic gastritis (yes, no), family history of gastric cancer (yes, no), and H. pylori infection (yes, no) when applicable. We also conducted subgroup analysis according to tumor localization: GCC vs NCGC using conditional logistic regression, and applied the Wald test to assess heterogeneity of the ORs. Two-sided $p<0.05$ was regarded as having statistical significance. SAS 9.4 was used for all statistical analyses.

\section{Results}

\section{Baseline}

A total of 299 cases of gastric cancer were included in the final analysis, consisting of GCC $(\mathrm{n}=122)$ and NCGC $(n=177)$ patients (Table 1). There were 96 patients with gastric cancer excluded due to the baseline diagnosis of diabetes. Both GCC and NCGC cases had lower levels of BMI, education, and monthly household income compared to controls (all $p<0.05$ ). Higher prevalence of chronic atrophic gastritis was observed in both GCC (29/122, $23.8 \%)$ and NCGC $(13 / 177,18.6 \%)$ compared to controls $(22 / 299,7.4 \%)$ (all $p<0.05)$. The prevalence of $H$. pylorinfection was observed lower in patients with GCC (31.6\%), compared to control participants $(45.1 \%)$.

\section{Distributions of Trace Elements}

Median serum concentrations of $\mathrm{Cu}$ were observed much higher in both GCC (1014.6 $\mu \mathrm{g} / \mathrm{L})$ and NCGC $(1000.2 \mu \mathrm{g} / \mathrm{L})$ cases compared to controls $(927.7 \mu \mathrm{g} / \mathrm{L})($ all $p<0.05)$ (Table 2$)$. The distributions of $\mathrm{Zn}$ and Se were similar between controls and all gastric cancer cases (all $p>0.05$ ). On the other hand, median serum concentrations of $\mathrm{Mo}, \mathrm{Fe}$, and $\mathrm{Ca}$ were all higher in gastric cancer groups than in controls.

\section{Serum Trace Elements in Relation to Gastric Cancer}

The highest level of $\mathrm{Cu}$ was observed with an OR of 2.42 (95\% CI: 1.10-5.32) for overall gastric cancer risk compared to the lowest reference group (Table 3). Doseresponse correlations were observed between the serum level of $\mathrm{Cu}$ and all subtypes of gastric cancer (all $p$ for trend $<0.05$ ). Study subjects with an intermediate level of Zn (quartile 3: 650.2-844.5 $\mu \mathrm{g} / \mathrm{L}$ ) were observed with lower risk of gastric cancer combined $\left(\mathrm{OR}_{4 \text { th }}\right.$ quartile $=0.25$, 95\% CI: $0.10-0.61)$, GCC $\left(\mathrm{OR}_{4 \text { th }}\right.$ quartile $=0.15,95 \% \mathrm{CI}$ :
$0.03-0.43)$, and NCGC ( $\left(\mathrm{OR}_{4 \text { th quartile }}=0.34,95 \%\right.$ CI: $0.13-$ 0.98). However, no dose-response association was observed in any of the case groups (all $p>0.05$ ).

The highest serum level of Se was inversely associated with risk of gastric cancer combined $\left(\mathrm{OR}_{4 \text { th }}\right.$ quartile $=0.33$, 95\% CI: $0.15-0.75)$, and this association seems limited to the NCGC subtype $\left(\mathrm{OR}_{4 \text { th }}\right.$ quartile $=0.18,95 \%$ CI: $0.07-$ 0.51). No associations were, however, observed between risk of GCC and Se concentration ( $p$ for trend $=0.43$ ). Comparing the highest to the lowest quartiles of Mo biomarkers, we found statistically inverse associations between this micro-element and overall risk of gastric cancer $\left(\mathrm{OR}_{4 \text { th }}\right.$ quartile $\left.=0.06,95 \% \mathrm{CI}: 0.02-0.20\right)$, as well as $\operatorname{GCC} \quad\left(\mathrm{OR}_{4 \text { th }}\right.$ quartile $\left.=0.12,95 \% \quad \mathrm{CI}: \quad 0.03-0.47\right)$. Meanwhile, dose-response associations were found for all case groups (all $p$ for trend $<0.05$ ).

No dose-response association was found for $\mathrm{Fe}$ in relation to any gastric cancer groups. However, a higher serum level of $\mathrm{Fe}$ was observed with more than $50 \%$ risk reduction for overall gastric cancer compared to the group with the lowest level of $\mathrm{Fe}\left(\mathrm{OR}_{4 \text { th }}\right.$ quartile $=0.41,95 \% \mathrm{CI}$ : 0.18-0.91). More specifically, this risk reduction by $\mathrm{Fe}$ might only affect $\mathrm{GCC}$ patients $\left(\mathrm{OR}_{3 \mathrm{rd}}\right.$ quartile $=0.18,95 \%$ CI: 0.05-0.70). Inverse dose-response associations were found between higher serum concentration of $\mathrm{Ca}$ and risk of all gastric cancer subgroups (all $p$ for trend $<0.05$ ). Compared to the lowest quartile of $\mathrm{Ca}$, the $\mathrm{OR}_{4 \text { th }}$ quartile calculated in the highest quartile was 0.04 (95\% CI: 0.010.11 ) for risk of gastric cancer combined, 0.06 (95\% CI: $0.01-0.26)$ for GCC cases, and 0.02 (95\% CI: $0.00-0.17)$ for NCGC cases.

No significant association was observed for serum level of $\mathrm{Mg}$ in relation to gastric cancer risk. But, meanwhile, we observed a strong positive doseresponse association between $\mathrm{Cu} / \mathrm{Zn}$ ratio and risk of all gastric cancer subgroups in the current study (all $p$ for trend $<0.05$ ). Study subjects with the highest $\mathrm{Cu} / \mathrm{Zn}$ ratio had a more than 10 -fold increased risk of gastric cancer combined $\left(\mathrm{OR}_{4 \text { th }}\right.$ quartile $=11.70,95 \% \mathrm{CI}: 3.83-$ 35.6), GCC $\left(\mathrm{OR}_{4 \text { th }}\right.$ quartile $\left.=9.03,95 \% \mathrm{CI}: 2.29-35.6\right)$, and NCGC $\left(\mathrm{OR}_{4 \text { th }}\right.$ quartile $=18.82,95 \%$ CI: $\left.3.50-96.01\right)$.

\section{Discussion}

The current study mainly reveals the role of serum trace elements in the development of gastric cancer. The results demonstrated strong inverse associations between serum $\mathrm{Se}, \mathrm{Mo}, \mathrm{Ca}$, and risk of gastric cancer. Meanwhile, high 
Table I Baseline Characteristics of Gastric Cancer and Control Participants in a Chinese Matched Case-Control Study

\begin{tabular}{|c|c|c|c|c|c|}
\hline Characteristics & $\begin{array}{l}\text { Control (\%) } \\
(n=299)\end{array}$ & $\begin{array}{l}\text { Cardia (\%) } \\
(n=122)\end{array}$ & $\begin{array}{l}\text { Noncardia (\%) } \\
(n=177)\end{array}$ & $p$ value $^{a}$ & $p$ value $^{b}$ \\
\hline Sex & & & & 0.45 & 0.57 \\
\hline Male & $231(77.3)$ & $90(73.4)$ & |4| (79.7) & & \\
\hline Female & $68(22.7)$ & $32(26.2)$ & $36(20.3)$ & & \\
\hline Age (mean \pm std, years) & $65.7 \pm 9.3$ & $68.0 \pm 8.7$ & $65.0 \pm 10.0$ & 0.05 & 0.40 \\
\hline Age Group (Years) & & & & 0.01 & 0.57 \\
\hline$<55$ & 35 (II.5) & $3(2.5)$ & $24(13.6)$ & & \\
\hline $55-64$ & $108(36.3)$ & $44(36.0)$ & $67(37.9)$ & & \\
\hline $65-74$ & $107(35.9)$ & $47(38.5)$ & $53(29.9)$ & & \\
\hline$\geq 75$ & $49(16.3)$ & $28(23.0)$ & $33(18.6)$ & & \\
\hline Body Mass Index $\left(\mathrm{kg} / \mathrm{m}^{2}\right)$ & & & & 0.003 & $<0.0001$ \\
\hline$<18.5$ & $27(9.0)$ & $21(17.2)$ & $44(24.8)$ & & \\
\hline $18.5-24.9$ & $229(76.5)$ & $94(77.1)$ & $125(70.6)$ & & \\
\hline$\geq 25$ & $43(14.5)$ & $7(5.7)$ & $8(4.6)$ & & \\
\hline Educational Level (Years) & & & & 0.0003 & 0.13 \\
\hline$<7$ & $200(66.8)$ & $104(85.3)$ & $134(75.7)$ & & \\
\hline $7-9$ & $60(20.1)$ & $15(12.3)$ & $28(I 5.8)$ & & \\
\hline$\geq 10$ & $39(13.1)$ & $3(2.5)$ & $15(8.5)$ & & \\
\hline Occupation & & & & 0.05 & 0.95 \\
\hline Farmer & $210(70.2)$ & $97(79.5)$ & $|2|(68.8)$ & & \\
\hline Industrial worker & $28(9.4)$ & $8(6.6)$ & $20(1 \mathrm{I} .4)$ & & \\
\hline Office worker & $58(19.4)$ & $17(13.9)$ & $34(19.3)$ & & \\
\hline Others & $3(1.0)$ & & I (0.6) & & \\
\hline Household Income (Yuan/Month/Person) & & & & $<0.000 \mathrm{I}$ & $<0.000$ I \\
\hline$<600$ & $138(46.2)$ & $25(20.7)$ & $44(25.0)$ & & \\
\hline $600-1000$ & $77(25.8)$ & $4 \mathrm{I}(33.9)$ & $53(30.1)$ & & \\
\hline$\geq 1000$ & $84(28.1)$ & $55(45.5)$ & $79(44.9)$ & & \\
\hline Tobacco Smoking & & & & 0.67 & 0.02 \\
\hline Yes & $154(5 \mid .5)$ & $60(49.2)$ & $111(63.1)$ & & \\
\hline No & $145(48.5)$ & $62(50.8)$ & $65(36.9)$ & & \\
\hline \multicolumn{6}{|l|}{ Alcohol Drinking } \\
\hline Yes & $46(15.4)$ & II (9.0) & $36(20.5)$ & 0.11 & 0.12 \\
\hline No & $253(84.6)$ & III (9I.0) & $140(79.5)$ & & \\
\hline Family History of Gastric Cancer & & & & 1.00 & 0.88 \\
\hline Yes & $53(32.9)$ & $17(33.3)$ & $22(34.4)$ & & \\
\hline No & $108(67.1)$ & $34(66.7)$ & $42(65.6)$ & & \\
\hline Chronic Atrophic Gastritis & & & & $<0.0001$ & 0.0001 \\
\hline Yes & $22(7.4)$ & $29(23.8)$ & $33(18.6)$ & & \\
\hline No & $277(92.6)$ & $93(76.2)$ & I44 (8I.4) & & \\
\hline Reflux & & & & 0.03 & 0.07 \\
\hline Yes & $78(30.2)$ & $47(83.9)$ & $21(20.8)$ & & \\
\hline No & $180(69.8)$ & $9(16.1)$ & $80(79.2)$ & & \\
\hline H. pylori infection & & & & 0.02 & 0.09 \\
\hline Positive & $124(45.1)$ & $36(31.6)$ & $59(36.4)$ & & \\
\hline Negative & 151 (54.9) & $78(68.4)$ & $103(63.6)$ & & \\
\hline
\end{tabular}

Notes: ${ }^{a} p$ value between the control and cardia groups using the chi-square test. ${ }^{b} p$ value between the control and noncardia groups using the chi-square test. 
Table 2 Distribution of Serum Level (Median and Interquartile Range) of Trace Elements in the Study Population ( $\mathrm{n}=594)$

\begin{tabular}{|c|c|c|c|c|c|}
\hline Trace elements & Controls & Cardia GC & Noncardia GC & $p$ value $^{a}$ & $p$ value $^{b}$ \\
\hline $\mathrm{Cu}($ median, IQR, $\mu \mathrm{g} / \mathrm{L}$ ) & $927.7(799.1-13 \mid 2.5)$ & $10 \mid 4.6(874.4-1309.2)$ & $1000.2(821.4-1226.3)$ & 0.0003 & 0.0009 \\
\hline Zn (median, IQR, $\mu g / L)$ & $605.3(492.76-804.54)$ & $545.6(394.9-729.5)$ & $554.6(428.8-761.7)$ & 0.47 & 0.52 \\
\hline Se (median, IQR, $\mu \mathrm{g} / \mathrm{L})$ & $92.14(69.9-116.7)$ & $90.9(63.5-1 \mid 2.6)$ & $90.2(65.5-112.6)$ & 0.28 & 0.16 \\
\hline Mo (median, IQR, $\mu \mathrm{g} / \mathrm{L}$ ) & $\mathrm{I} .8(0.93-2.79)$ & $0.93(0.72-1.14)$ & $0.93(0.78-1.14)$ & $<0.0001$ & $<0.0001$ \\
\hline Fe (median, IQR, $\mu g / L)$ & I 109.8 (890.0-1454.3) & $925.4(809.6-|1| 2 \mid .0)$ & $936.6(780.3-1164.8)$ & $<0.0001$ & 0.97 \\
\hline $\mathrm{Ca}$ (median, IQR, mg/L) & $85.1(74.9-103.2)$ & $66.7(59.1-75.2)$ & $68.9(60.3-78.5)$ & $<0.0001$ & $<0.0001$ \\
\hline Mg (median, IQR, mg/L) & $19.1(17.9-20.6)$ & $20.1(\mid 8.1-21.9)$ & $19.8(\mid 8.2-22.1)$ & 0.08 & 0.11 \\
\hline $\mathrm{Cu} / \mathrm{Zn}$ ratio (median, IQR) & $1.43(1.07-1.84)$ & $2.16(1.5 \mathrm{I}-2.98)$ & $1.91(1.53-2.46)$ & $<0.0001$ & $<0.0001$ \\
\hline
\end{tabular}

Notes: ${ }^{a} p$ value comparing the mean value of trace elements between controls and gastric cardia cancers; normal distribution used the T-test, non-normal distribution used the Wilcoxon rank-sum test. ${ }^{b} p$ value comparing the mean value of trace elements between controls and gastric noncardia cancers; normal distribution used the $T$-test, nonnormal distribution used the Wilcoxon rank-sum test.

serum concentrations of $\mathrm{Cu}$ and $\mathrm{Cu} / \mathrm{Zn}$ ratio related to increased risk of gastric cancer.

The data from the present study are consistent with the impression that high serum Se may be associated with a decreased risk of gastric cancer. Previous studies have shown that Se may have anti-carcinogenic effects, especially against cancers of the lung, prostate, skin, and gastrointestinal system. ${ }^{23,24}$ One study observed significantly lower serum levels of Se in the esophageal cancer group, as compared with normal healthy controls. ${ }^{25}$ A nutrition intervention trial conducted in Linxian County among the general population observed lower mortality of gastric cancer in participant groups receiving supplementation with vitamins and minerals (including Se) than in individuals who did not receive the supplements. ${ }^{26}$ Of note, Linxian County is also a rural area with poor socioeconomic status and well known for its high incidence of gastric cancer, which is very similar to the study region of the current study. ${ }^{27}$ Furthermore, it is worth mentioning that the inverse association between Se level and gastric cancer may only occur in populations with low Se levels. ${ }^{28}$ A serum level of Se below $70 \mu \mathrm{g} / \mathrm{L}$ is usually considered a deficiency. ${ }^{29}$ According to this standard, $25.4 \%$ of our controls (76/299) and $34.1 \%$ of all gastric cancer cases (102/299) were considered to be Se deficient. It could be inferred that a low level of Se might contribute partly to the high incidence of gastric cancer found in Xianyou County.

Essential elements $\mathrm{Cu}$ and $\mathrm{Zn}$ have a role in many biochemical reactions as a micro-source. ${ }^{30} \mathrm{Zn}$ alone has been associated with risk of gastric cancer, but the epidemiological findings have been quite limited and controversial. Zhang et al have observed higher serum concentration of $\mathrm{Zn}$ in gastric cancer cases than healthy controls. ${ }^{12}$
However, a Japanese study found no excess risk of gastric cancer among those with the lowest levels of $\mathrm{Zn}$ $(\mathrm{OR}=1.2) .{ }^{31}$ Although in our study decreased risks of gastric cancer were found in the third quartile of serum $\mathrm{Zn}$, the linear association was not statistically significant. On the other hand, a higher level of $\mathrm{Cu}$ was also observed associated with higher risk of gastric cancer in the current study. Our result is partly supported by previous studies which detected a higher level of $\mathrm{Cu}$ in gastric cancer cases compared to healthy controls. ${ }^{32}$ It has been known that $\mathrm{Cu}$ participates in the reductive activation of $\mathrm{H}_{2} \mathrm{O}_{2}$, causing damage to cellular DNA, proteins, and lipids. The interaction of $\mathrm{H}_{2} \mathrm{O}_{2}$ with $\mathrm{Cu}$ generates more reactive oxygen species, such as hydroxyl radicals, eg, $\bullet \mathrm{OH}$. These reactive oxygen species have been considered as being responsible for the process of carcinogenesis. ${ }^{33}$

There are also controversial data regarding the association between $\mathrm{Cu} / \mathrm{Zn}$ and several cancers. Our results suggest that the $\mathrm{Cu} / \mathrm{Zn}$ was positively associated with increased risk of gastric cancer, which was inconsistent with a previous study. ${ }^{16}$ Similarly, higher levels of $\mathrm{Cu} / \mathrm{Zn}$ ratio have been previously declared in many types of cancers including head and neck cancer, endometrial cancer, colon cancer, and bladder carcinoma. ${ }^{32,34-37}$ However, the exact role of these metals in the carcinogenic process has not yet been clearly understood. $\mathrm{Cu} / \mathrm{Zn}$ ratio and systemic oxidant load have clinical importance for agingrelated degenerative diseases, nutritional status, oxidative stress, inflammation, and immune abnormalities which may affect carcinogenesis. ${ }^{14,15,38-40}$ Mezzetti et $\mathrm{al}^{38}$ reported advanced age, and, particularly, advanced agerelated chronic degenerative diseases are associated with a significant increase in the $\mathrm{Cu} / \mathrm{Zn}$ ratio and systemic oxidative stress. Gaider et $\mathrm{al}^{39}$ stated that higher $\mathrm{Cu} / \mathrm{Zn}$ 
Table 3 Risk Assessment of Gastric Cancer, Expressed as Odds Ratio (OR) and 95\% Confidence Interval (Cl), in a Chinese CaseControl Study

\begin{tabular}{|c|c|c|c|c|c|c|c|}
\hline \multirow[t]{2}{*}{ Variables } & \multirow{2}{*}{$\begin{array}{l}\text { Controls } \\
\mathbf{N}(\%)\end{array}$} & \multicolumn{2}{|c|}{ All Gastric Cancer } & \multicolumn{2}{|c|}{ Gastric Cardia Cancer } & \multicolumn{2}{|c|}{ Gastric Noncardia Cancer } \\
\hline & & $\mathbf{N}(\%)$ & $O R^{a}(95 \% \mathrm{Cl})$ & N (\%) & $O R^{a}(95 \% \mathrm{Cl})$ & N (\%) & $O R^{a}(95 \% C l)$ \\
\hline $\begin{array}{l}\text { Cu (Quartile) } \\
\text { Q1: <799.I } \\
\text { Q2: 799.I-927.9 } \\
\text { Q3: 927.9-1059.8 } \\
\text { Q4: >1059.8 } \\
\text { p for trend }\end{array}$ & $\begin{array}{l}74(24.75) \\
77(25.76) \\
74(24.75) \\
74(24.75)\end{array}$ & $\begin{array}{l}55(18.39) \\
51(17.06) \\
61(20.40) \\
132(44.15)\end{array}$ & $\begin{array}{l}1.00 \\
0.73(0.30-1.83) \\
1.01(0.44-2.34) \\
2.42(1.10-5.32) \\
0.003\end{array}$ & $\begin{array}{ll}20 & (16.39) \\
21 & (17.2) \\
23 & (18.9) \\
58 & (47.5)\end{array}$ & $\begin{array}{l}1.00 \\
0.62(0.18-2.21) \\
0.48(0.15-1.56) \\
2.48(0.94-6.54) \\
0.01\end{array}$ & $\begin{array}{l}35(19.77) \\
30(16.95) \\
38(21.47) \\
74(4 I .8 I)\end{array}$ & $\begin{array}{l}1.00 \\
0.74(0.22-2.48) \\
1.39(0.48-3.90) \\
2.39(0.84-6.86) \\
0.03\end{array}$ \\
\hline $\begin{array}{l}\text { Zn (Quartile) } \\
\text { QI: <492.8 } \\
\text { Q2: 492.8-650.2 } \\
\text { Q3: 650.2-844.5 } \\
\text { Q4: >844.2 } \\
\text { p for trend }\end{array}$ & $\begin{array}{l}74(24.75) \\
76(25.42) \\
74(24.75) \\
75(25.08)\end{array}$ & $\begin{array}{l}\text { II } 4(38.13) \\
75(25.08) \\
44(14.72) \\
66(22.07)\end{array}$ & $\begin{array}{l}1.00 \\
0.45(0.18-1.09) \\
0.25(0.10-0.61) \\
0.59(0.26-1.35) \\
0.22\end{array}$ & $\begin{array}{ll}53 & (43.44) \\
24 & (19.67) \\
17 & (13.93) \\
28 & (22.95)\end{array}$ & $\begin{array}{l}1.00 \\
0.40(0.12-1.36) \\
0.15(0.03-0.43) \\
0.82(0.29-2.24) \\
0.54\end{array}$ & $\begin{array}{ll}6 I & (34.46) \\
5 I & (28.8 I) \\
27 & (15.25) \\
38 & (2 I .47)\end{array}$ & $\begin{array}{l}1.00 \\
0.50(0.18-1.42) \\
0.34(0.13-0.98) \\
0.56(0.19-1.59) \\
0.25\end{array}$ \\
\hline $\begin{array}{l}\text { Se (Quartile) } \\
\text { Q1: <69.6 } \\
\text { Q2: 69.6-92.I } \\
\text { Q3: } 92.1-118.8 \\
\text { Q4: >118.8 } \\
\text { p for trend }\end{array}$ & $\begin{array}{l}73(24.4 I) \\
74(24.75) \\
76(25.42) \\
76(25.42)\end{array}$ & $\begin{array}{l}97(32.44) \\
67(22.4 I) \\
67(22.4 I) \\
68(22.74)\end{array}$ & $\begin{array}{l}1.00 \\
0.47(0.20-1.08) \\
0.44(0.19-1.01) \\
0.33(0.15-0.75) \\
0.009\end{array}$ & $\begin{array}{ll}39 & (31.97) \\
25 & (20.49) \\
31 & (25.4 I) \\
27 & (22.13)\end{array}$ & $\begin{array}{l}1.00 \\
0.95(0.34-2.68) \\
0.55(0.17-1.70) \\
0.72(0.25-2.02) \\
0.43\end{array}$ & $\begin{array}{l}58(32.77) \\
42(23.73) \\
36(20.34) \\
41(23.16)\end{array}$ & $\begin{array}{l}1.00 \\
0.20(0.06-0.62) \\
0.38(0.14-1.01) \\
0.18(0.07-0.51) \\
0.001\end{array}$ \\
\hline $\begin{array}{l}\text { Mo (Quartile) } \\
\text { Q1: <0.93 } \\
\text { Q2: 0.93-1.8I } \\
\text { Q3: } 1.81-2.79 \\
\text { Q4: >2.79 } \\
\text { p for trend }\end{array}$ & $\begin{array}{ll}60 & (20.00) \\
89 & (29.83) \\
69 & (23.05) \\
81 & (27.12)\end{array}$ & $\begin{array}{l}\text { I } 43(47.83) \\
137(45.82) \\
12(4.01) \\
7(2.34)\end{array}$ & $\begin{array}{l}1.00 \\
0.86(0.43-1.73) \\
0.07(0.02-0.21) \\
0.06(0.02-0.20) \\
<0.0001\end{array}$ & $\begin{array}{l}60(49.18) \\
54(44.26) \\
3(2.46) \\
5(4.10)\end{array}$ & $\begin{array}{l}1.00 \\
0.78(0.31-1.83) \\
0.04(0.004-0.29) \\
0.12(0.03-0.47) \\
<0.0001\end{array}$ & $\begin{array}{l}83(46.89) \\
83(46.89) \\
9(5.08) \\
2(1.13)\end{array}$ & $\begin{array}{l}1.00 \\
0.87(0.37-2.06) \\
0.10(0.02-0.41) \\
- \\
0.001\end{array}$ \\
\hline $\begin{array}{l}\text { Fe (Quartile) } \\
\text { Q1: <890.0 } \\
\text { Q2: 890.0-I1 } 09.8 \\
\text { Q3: I109.8-1454.3 } \\
\text { Q4: > |454.3 } \\
\text { p for trend }\end{array}$ & $\begin{array}{l}74(24.75) \\
75(25.08) \\
73(24.4 I) \\
77(25.76)\end{array}$ & $\begin{array}{l}122(72.58) \\
84(28.09) \\
38(12.7 \mid) \\
55(18.39)\end{array}$ & $\begin{array}{l}1.00 \\
0.43(0.19-0.95) \\
0.27(0.11-0.68) \\
0.41(0.18-0.91) \\
0.07\end{array}$ & $\begin{array}{ll}51 & (4 I .80) \\
34 & (27.87) \\
16 & (13.1 I) \\
21 & (17.2 I)\end{array}$ & $\begin{array}{l}1.00 \\
0.37(0.13-1.07) \\
0.18(0.05-0.70) \\
0.44(0.16-1.21) \\
0.17\end{array}$ & $\begin{array}{l}71(40.11) \\
50(28.25) \\
22(12.43) \\
34(19.21)\end{array}$ & $\begin{array}{l}1.00 \\
0.53(0.20-1.37) \\
0.41(0.14-1.21) \\
0.52(0.19-1.37) \\
0.25\end{array}$ \\
\hline $\begin{array}{l}\text { Ca (Quartile) } \\
\text { Q1: <75.3 } \\
\text { Q2: 75.3-86.I } \\
\text { Q3: 86.I-104.5 } \\
\text { Q4: >104.5 } \\
\text { p for trend }\end{array}$ & $\begin{array}{l}74(24.75) \\
76(25.42) \\
74(24.75) \\
75(25.08)\end{array}$ & $\begin{array}{l}217(72.58) \\
38(12.7 \mid) \\
31(10.37) \\
13(4.35)\end{array}$ & $\begin{array}{l}1.00 \\
0.06(0.02-0.16) \\
0.09(0.03-0.25) \\
0.04(0.01-0.11) \\
<0.0001\end{array}$ & $\begin{array}{l}91 \text { (74.59) } \\
\text { I4 (I I.48) } \\
\text { II (9.02) } \\
6(4.92)\end{array}$ & $\begin{array}{l}1.00 \\
0.05(0.01-0.22) \\
0.04(0.01-0.20) \\
0.06(0.01-0.26) \\
<0.0001\end{array}$ & $\begin{array}{l}126(71.19) \\
24(13.56) \\
20(11.30) \\
7(3.95)\end{array}$ & $\begin{array}{l}1.00 \\
0.06(0.02-0.27) \\
0.13(0.04-0.40) \\
0.02(0.00-0.17) \\
<0.001\end{array}$ \\
\hline $\begin{array}{l}\text { Mg (Quartile) } \\
\text { Q1: <17.8 } \\
\text { Q2: 17.8-19.2 } \\
\text { Q3: 19.2-20.8 } \\
\text { Q4: >20.8 } \\
\text { p for trend }\end{array}$ & $\begin{array}{l}74(24.75) \\
75(25.08) \\
76(25.42) \\
74(24.75)\end{array}$ & $\begin{array}{l}56(18.73) \\
61(20.40) \\
69(23.08) \\
111(37.79)\end{array}$ & $\begin{array}{l}1.00 \\
0.65(0.27-1.58) \\
1.06(0.43-2.66) \\
1.31(0.59-2.91) \\
0.23\end{array}$ & $\begin{array}{ll}22 & (18.03) \\
27 & (22.13) \\
23 & (18.85) \\
50 & (40.98)\end{array}$ & $\begin{array}{l}1.00 \\
0.99(0.30-3.22) \\
1.28(0.36-4.49) \\
1.68(0.56-4.84) \\
0.25\end{array}$ & $\begin{array}{l}34(19.21) \\
34(19.21) \\
46(25.99) \\
63(35.59)\end{array}$ & $\begin{array}{l}1.00 \\
0.49(0.16-1.5 \mathrm{I}) \\
1.02(0.34-3.01) \\
1.26(0.48-3.33) \\
0.28\end{array}$ \\
\hline
\end{tabular}


Table 3 (Continued).

\begin{tabular}{|c|c|c|c|c|c|c|c|}
\hline \multirow[t]{2}{*}{ Variables } & \multirow{2}{*}{$\begin{array}{l}\text { Controls } \\
\mathbf{N}(\%)\end{array}$} & \multicolumn{2}{|c|}{ All Gastric Cancer } & \multicolumn{2}{|c|}{ Gastric Cardia Cancer } & \multicolumn{2}{|c|}{ Gastric Noncardia Cancer } \\
\hline & & $\mathbf{N}(\%)$ & $O R^{a}(95 \% C l)$ & $\mathbf{N}(\%)$ & $O R^{a}(95 \% \mathrm{Cl})$ & $\mathbf{N}(\%)$ & $O R^{a}(95 \% \mathrm{Cl})$ \\
\hline \multicolumn{8}{|l|}{$\mathrm{Cu} / \mathrm{Zn}$ ratio (Quartile) } \\
\hline QI: $<1.08$ & $74(24.75)$ & $19(6.35)$ & 1.00 & $6(4.92)$ & 1.00 & $13(7.34)$ & 1.00 \\
\hline Q2: $1.08-1.44$ & $76(25.42)$ & $48(16.05)$ & $1.75(0.54-5.74)$ & $23(18.85)$ & $0.65(0.12-3.52)$ & $25(14.12)$ & $4.02(0.74-22.01)$ \\
\hline Q3: I.44-I.86 & $75(25.08)$ & $63(21.07)$ & $1.91(0.57-6.37)$ & $17(13.93)$ & $1.07(0.22-5.20)$ & $46(25.99)$ & $3.87(0.67-22.9)$ \\
\hline Q4: >1.86 & $74(24.75)$ & $169(56.52)$ & $11.70(3.83-35.6)$ & $76(62.32)$ & $9.03(2.29-35.6)$ & $93(52.54)$ & I8.82 (3.50-96.0I) \\
\hline$p$ for trend & & & $<0.0001$ & & $<0.0001$ & & $<0.0001$ \\
\hline
\end{tabular}

Notes: ${ }^{a}$ Adjusted for age group $\left(<45,45-55,56-65,66-75, \geq 76\right.$ years), sex (male, female), body mass index $\left(<18.5,18.5-24.9, \geq 25 \mathrm{~kg} / \mathrm{m}^{2}\right)$, education level $(<7,7-9, \geq 10$ years), occupation (farmer, industrial worker, office worker, others), household income $(<600,600-1000, \geq 1000$ Chinese Yuan/month/person), smoking (yes, no), family history of gastric cancer (yes, no), and $H$. pylori infection (yes, no).

ratios correlate with impairments in bone density, physical performance, and overall health in a population of elderly men with frailty characteristics. In peritoneal dialysis patients, elevated $\mathrm{Cu} / \mathrm{Zn}$ ratios are found to be associated with malnutrition, increased oxidative stress, inflammation, and disrupted immune status. ${ }^{40}$

Our results found limited evidence for the association between serum Fe status and GCC and all gastric cancer combined, which is partly consistent with those from previous studies. In the European Prospective Investigation into Cancer and Nutrition (EPIC) study, inverse doseresponse associations were found between serum $\mathrm{Fe}$ and overall risk of gastric cancer $\left(\mathrm{OR}_{4 \text { th vs } 1 \text { st quartile }}=0.62,95 \%\right.$ CI: $0.44-0.88, p$ for trend $=0.034$ ), as well as NCGC $\left(\mathrm{OR}_{4 \text { th }}\right.$ vs 1 st quartile $=0.54,95 \% \mathrm{CI}: 0.33-0.89, p$ for trend $=0.029) .{ }^{41}$ Similarly, a Finnish men cohort study also found serum $\mathrm{Fe}$ had an inverse or possibly "U"shaped relationship with this malignancy in the NCGC site $\left(\mathrm{OR}_{3 \mathrm{rd}}\right.$ vs 1 st quartile $=0.39,95 \% \mathrm{CI}: 0.19-0.78, p$ for trend $=0.06$ ), although the trend analysis was not statistically significant. ${ }^{41}$ In another Finnish cohort study, which involved 120 incident male gastric cancers and 76 female gastric cancers, the relationship in males was statistically significant $\left(\mathrm{RR}_{4 \text { th vs } 1 \text { st quartile }}=0.60, p\right.$ for trend $\left.<0.01\right) .{ }^{42}$

The present study also observed a lower risk of gastric cancer, regardless of GCC or NCGC, in the higher quartile of serum Mo, indicating the protective role of Mo in the development of these diseases. However, little evidence exists to explain the effects of serum Mo on gastric cancer. An earlier Chinese study showed that serum Mo levels of 33 patients with gastric cancer were significantly lower than those of 77 healthy controls. ${ }^{43}$ Their results also showed a negative correlation $(r=-0.285, P<0.01)$ between soil Mo and the mortality rate of gastric cancer. These results were actually supported by another study, showing that the Mo level in the mucosa of patients with gastritis, gastric ulcer, or gastric cancer was lower than that of normal people. ${ }^{44}$ These findings indicated that Mo deficiency may be an important risk factor in the development of gastric cancer. Two potential mechanisms have been raised. Mo has been observed with a direct anti-carcinogenic effect on mouse $N$-nitroso-sarcosine-ethyl-induced foregastric squamosum carcinoma. ${ }^{45}$ It was assumed that Mo might speed up detoxification of carcinogens through the effect on cytochrome P-450 in cells and demethylase. ${ }^{46}$ Another potential anti-carcinogenic mechanism could be attributed to the essential role of Mo, a component of nitrite reductase, in the transformation process of nitrate to nitrogen in the environment. Deficiency of Mo in the soil could reduce the conversion of nitrate, and consequently leave more carcinogenic nitrite in the environment. The serum level of Mo could be considered a proxy indicator for the Mo level in the environment. Due to scarce epidemiological data, the appropriate amount of serum Mo in humans warrants further investigations.

Some methodological issues of our study deserve attention. The strengths include the large sample size; individual matching for age, sex, resident region by gastric cancer risk and H. pylori infection status; the standardized tumor classification; the personal interviews with all study participants in a standard and strict manner; and stratified analysis by different gastric cancer localization. Meanwhile, our study has some limitations that should be described. A major concern is the possibility of exposure misclassification using a questionnaire that has not been validated. However, the reliability rate of our questionnaire was estimated as high as $97 \%$, suggesting the potential of high accuracy in measuring risk factors (data 
not shown). Secondly, the serum level of trace elements based on one single blood sample might also cause some information bias. Further study could be guaranteed by collecting several blood samples at different time points within a day, or different seasons within a year, and using the average level as the true level of a serum trace element. Finally, we were not able to adjust for types of medication taken in the past 1 month. Use of several types of medicines has been observed to influence the serum trace element. For example, an earlier study demonstrated that statin treatment was associated with a significant reduction in mean serum $\mathrm{Zn}(9 \%, p=0.03)$ and $\mathrm{Cu}(9 \%, p<0.01) .{ }^{47}$ Although we did ask participants about the type of medication taken in the past months, only 8 cardia patients, 3 noncardia patients, and 73 controls provided details. Due to the limited responses, we were not able to adjust medication use in the analysis. Further study is warranted with more details on medication taken prior to the data collection.

In conclusion, the study suggested that lower levels of $\mathrm{Se}, \mathrm{Mo}$, and $\mathrm{Ca}$ and higher levels of $\mathrm{Cu}$ and $\mathrm{Cu} / \mathrm{Zn}$ ratio may play an important role in gastric cancer induction. However, the results shall be carefully interpreted before further in vivo animal studies show definitive evidence.

\section{Abbreviations}

GCC, gastric cardia cancer; NCGC, noncardia gastric cancer.

\section{Ethics and Consent Statement}

This study was conducted according to the guidelines laid down in the Declaration of Helsinki and all procedures involving human subjects/patients were approved by the Fujian Medical University (ID: 201297). Written informed consent was obtained from all subjects/patients at the study enrollment.

\section{Data Sharing Statement}

The datasets analyzed during the current study are not publicly available due to that they concern personal information of study participants, but are available from the corresponding author on reasonable request.

\section{Author Contributions}

All authors contributed to data analysis, drafting or revising the article, gave final approval of the version to be published, and agree to be accountable for all aspects of the work.

\section{Funding}

This work was supported by the Natural Science Foundation of Fujian Province, China (Grant No. 2015J01673; 2017J01811; 2018J01825); Fujian Innovative Medicine (Grant No. 2016-CX-41); Xianyou County Government of Putian, Fujian, China (Grant No. 2013B008); Cultivation Program for Distinguished Young Scholar of Fujian Province University (Grant No. 2017B020); and Fujian Medical University's Research Foundation for Talented Scholars (Grant No. XRCZX2017012). All these funding did not involve in study design and collection, data analysis, and manuscript writing.

\section{Disclosure}

The authors report no conflicts of interest in this work.

\section{References}

1. Parkin DM, Bray F, Ferlay J, Pisani P. Global cancer statistics, 2002. CA Cancer J Clin. 2005;55(2):74-108.

2. Kolonel LN, Nomura AM, Hirohata T, Hankin JH, Hinds MW. Association of diet and place of birth with stomach cancer incidence in Hawaii Japanese and Caucasians. Am J Clin Nutr. 1981;34 (11):2478-2485. doi:10.1093/ajcn/34.11.2478

3. Haenszel W, Kurihara M. Studies of Japanese migrants. I. Mortality from cancer and other diseases among Japanese in the United States. J Natl Cancer Inst. 1968;40(1):43-68.

4. Khlifi R, Olmedo P, Gil F, et al. Arsenic, cadmium, chromium and nickel in cancerous and healthy tissues from patients with head and neck cancer. Sci Total Environ. 2013;452-453:58-67. doi:10.1016/j. scitotenv.2013.02.050

5. Ho E. Zinc deficiency, DNA damage and cancer risk. J Nutr Biochem. 2004;15(10):572-578. doi:10.1016/j.jnutbio.2004.07.005

6. Patrick L. Selenium biochemistry and cancer: a review of the literature. Altern Med Rev. 2004;9(3):239-258.

7. Uriu-Adams JY, Keen CL. Copper, oxidative stress, and human health. Mol Aspects Med. 2005;26(4-5):268-298. doi:10.1016/j. mam.2005.07.015

8. Ramoutar RR, Brumaghim JL. Antioxidant and anticancer properties and mechanisms of inorganic selenium, oxo-sulfur, and oxo-selenium compounds. Cell Biochem Biophys. 2010;58(1):1-23. doi:10.1007/ s12013-010-9088-x

9. Nelson WG, De Marzo AM, Isaacs WB. Prostate cancer. $N$ Engl J Med. 2003;349(4):366-381. doi:10.1056/NEJMra021562

10. Nouarie M, Pourshams A, Kamangar F, et al. Ecologic study of serum selenium and upper gastrointestinal cancers in Iran. World $J$ Gastroenterol. 2004;10(17):2544-2546. doi:10.3748/wjg.v10. i17.2544

11. Campos FI, Koriyama C, Akiba S, et al. Toenail zinc level and gastric cancer risk in Cali, Colombia. J Cancer Res Clin Oncol. 2008;134 (2):169-178. doi:10.1007/s00432-007-0266-1

12. Zhang WH, Wu XJ, Niu JX, et al. Serum zinc status and helicobacter pylori infection in gastric disease patients. Asian Pac J Cancer Prev. 2012;13(10):5043-5046. doi:10.7314/APJCP.2012.13.10.5043

13. Kohzadi S, Sheikhesmaili F, Rahehagh R, et al. Evaluation of trace element concentration in cancerous and non-cancerous tissues of human stomach. Chemosphere. 2017;184:747-752. doi:10.1016/j. chemosphere.2017.06.071 
14. Murakami M, Hirano T. Intracellular zinc homeostasis and zinc signaling. Cancer Sci. 2008;99(8):1515-1522. doi:10.1111/j.13497006.2008.00854.x

15. Lowndes SA, Adams A, Timms A, et al. Phase I study of copperbinding agent ATN-224 in patients with advanced solid tumors. Clin Cancer Res. 2008;14(22):7526-7534. doi:10.1158/1078-0432.CCR08-0315

16. Lin Y, Kikuchi S, Obata Y, Yagyu K. Tokyo research group on prevention of gastric C. Serum copper/zinc superoxide dismutase ( $\mathrm{Cu} / \mathrm{Zn} \mathrm{SOD})$ and gastric cancer risk: a case-control study. Jpn J Cancer Re. 2002;93 (10):1071-1075. doi:10.1111/j.1349-7006.2002.tb01207.x

17. Fonseca-Nunes A, Jakszyn P, Agudo A. Iron and cancer risk-a systematic review and meta-analysis of the epidemiological evidence. Cancer Epidemiol Biomarkers Prev. 2014;23(1):12-31. doi:10.1158/ 1055-9965.EPI-13-0733

18. Li D, Wu C, Cai Y, Liu B. Association of NFKB1 and NFKBIA gene polymorphisms with susceptibility of gastric cancer. Tumour Biol. 2017;39(7):1010428317717107. doi:10.1177/1010428317717107

19. Lu HD, Wang ZQ, Pan YR, Zhou TS, Xu XZ, Ke TW. Comparison of serum $\mathrm{Zn}, \mathrm{Cu}$ and Se contents between healthy people and patients in high, middle and low incidence areas of gastric cancer of Fujian Province. World J Gastroenterol. 1999;5(1):84-86. doi:10.3748/wjg.v5.i1.84

20. Tepes B. Comparison of two invasive diagnostic tests for Helicobacter pylori after antimicrobial therapy. Scand J Gastroenterol. 2007;42 (3):330-332. doi:10.1080/00365520601009778

21. Karakus C, Salih BA. Comparison of the lateral flow immunoassays (LFIA) for the diagnosis of Helicobacter pylori infection. J Immunol Methods. 2013;396(1-2):8-14. doi:10.1016/j.jim.2013.08.010

22. Dong X, Hu F, Gao W, et al. [Detection of Helicobacter pylori by immunoblot: a multiple-center study]. Zhonghua Yi Xue Za Zhi. 2016;96(4):265-269. doi:10.3760/cma.j.issn.0376-2491.2016.04.007 (Article in Chinese)

23. Rayman MP. Selenium in cancer prevention: a review of the evidence and mechanism of action. Proc Nutr Soc. 2005;64(4):527-542. doi:10.1079/PNS2005467

24. Lee SR, Bar-Noy S, Kwon J, Levine RL, Stadtman TC, Rhee SG. Mammalian thioredoxin reductase: oxidation of the C-terminal cysteine/selenocysteine active site forms a thioselenide, and replacement of selenium with sulfur markedly reduces catalytic activity. Proc Natl Acad Sci US A. 2000;97(6):2521-2526. doi:10.1073/ pnas.050579797

25. Goyal MM, Kalwar AK, Vyas RK, Bhati A. A study of serum zinc, selenium and copper levels in carcinoma of esophagus patients. Indian J Clin Biochem. 2006;21(1):208-210. doi:10.1007/BF02913100

26. Qiao YL, Dawsey SM, Kamangar F, et al. Total and cancer mortality after supplementation with vitamins and minerals: follow-up of the linxian general population nutrition intervention trial. J Natl Cancer Inst. 2009;101(7):507-518. doi:10.1093/jnci/djp037

27. Yang L. Incidence and mortality of gastric cancer in China. World $J$ Gastroenterol. 2006;12(1):17-20. doi:10.3748/wjg.v12.i1.17

28. Koriyama C, Campos FI, Yamamoto M, et al. Toenail selenium levels and gastric cancer risk in Cali, Colombia. J Toxicol Sci. 2008;33 (2):227-235. doi:10.2131/jts.33.227

29. Dietary Reference Intakes for Vitamin C, Vitamin E, Selenium, and Carotenoids. Washington (DC); 2000.

30. Magalova T, Bella V, Brtkova A, Beno I, Kudlackova M, Volkovova $\mathrm{K}$. Copper, zinc and superoxide dismutase in precancerous, benign diseases and gastric, colorectal and breast cancer. Neoplasma. 1999;46(2):100-104.
31. Kabuto M, Imai H, Yonezawa C, et al. Prediagnostic serum selenium and zinc levels and subsequent risk of lung and stomach cancer in Japan. Cancer Epidemiol Biomarkers Prev. 1994;3(6):465-469.

32. Boz A, Evliyaoglu O, Yildirim M, Erkan N, Karaca B. The value of serum zinc, copper, ceruloplasmin levels in patients with gastrointestinal tract cancers. Turk J Gastroenterol. 2005;16(2):81-84.

33. Huang YL, Sheu JY, Lin TH. Association between oxidative stress and changes of trace elements in patients with breast cancer. Clin Biochem. 1999;32(2):131-136. doi:10.1016/S0009-9120(98)00096-4

34. Golabek T, Darewicz B, Borawska M, Socha K, Markiewicz R, Kudelski J. Copper, zinc, and $\mathrm{Cu} / \mathrm{Zn}$ ratio in transitional cell carcinoma of the bladder. Urol Int. 2012;89(3):342-347. doi:10.1159/ 000341976

35. Buntzel J, Bruns F, Glatzel M, et al. Zinc concentrations in serum during head and neck cancer progression. Anticancer Res. 2007;27 (4A):1941-1943.

36. John S, Briatka T, Rudolf E. Diverse sensitivity of cells representing various stages of colon carcinogenesis to increased extracellular zinc: implications for zinc chemoprevention. Oncol Rep. 2011;25(3):769780. doi:10.3892/or.2010.1124

37. Atakul T, Altinkaya SO, Abas BI, Yenisey C. Serum copper and zinc levels in patients with endometrial cancer. Biol Trace Elem Res. 2019. doi:10.1007/s12011-019-01844-x

38. Mezzetti A, Pierdomenico SD, Costantini F, et al. Copper/zinc ratio and systemic oxidant load: effect of aging and aging-related degenerative diseases. Free Radic Biol Med. 1998;25(6):676-681. doi:10.1016/S0891-5849(98)00109-9

39. Gaier ED, Kleppinger A, Ralle M, Mains RE, Kenny AM, Eipper BA. High serum $\mathrm{Cu}$ and $\mathrm{Cu} / \mathrm{Zn}$ ratios correlate with impairments in bone density, physical performance and overall health in a population of elderly men with frailty characteristics. Exp Gerontol. 2012;47 (7):491-496. doi:10.1016/j.exger.2012.03.014.

40. Guo CH, Chen PC, Yeh MS, Hsiung DY, Wang CL. Cu/Zn ratios are associated with nutritional status, oxidative stress, inflammation, and immune abnormalities in patients on peritoneal dialysis. Clin Biochem. 2011;44(4):275-280. doi:10.1016/j.clinbiochem.2010.12.017.

41. Cook MB, Kamangar F, Weinstein SJ, et al. Iron in relation to gastric cancer in the Alpha-tocopherol, Beta-carotene cancer prevention study. Cancer Epidemiol Biomarkers Prev. 2012;21(11):2033-2042. doi:10.1158/1055-9965.EPI-12-0799

42. Knekt P, Reunanen A, Takkunen H, Aromaa A, Heliovaara M, Hakulinen T. Body iron stores and risk of cancer. Int $J$ Oncol. 1994;56(3):379-382. doi:10.1002/ijc.2910560315

43. Cao G, Yan S, Yuan Z, Wu L, Liu Y. A study of the relationship between trace element Mo and gastric cancer. World J Gastroenterol. 1998;4(1):55-56. doi:10.3748/wjg.v4.i1.55

44. Zhou W, He L, Lin W, Luo J. Trace element measurement in gastric mucosa of gastric disease patients. Guangxi Med. 1990;12(5):298300 .

45. Wei H. Effect of molybdenum on N-nitroso-sarcosine-ethyl causing mouse foregastric squamosum carcinoma. Trace Element. 1986;2:6-8.

46. Miller E. Some current perspectives on chemical carcinogenesis in human and experimental animals. Cancer Res. 1978;38:1479.

47. Correa P. Human gastric carcinogenesis: a multistep and multifactorial process-First American Cancer Society Award Lecture on Cancer Epidemiology and Prevention. Cancer Res. 1992;52(24):6735-6740. 


\section{Publish your work in this journal}

Cancer Management and Research is an international, peer-reviewed open access journal focusing on cancer research and the optimal use of preventative and integrated treatment interventions to achieve improved outcomes, enhanced survival and quality of life for the cancer patient
The manuscript management system is completely online and includes a very quick and fair peer-review system, which is all easy to use. Visit http://www.dovepress.com/testimonials.php to read real quotes from published authors.

Submit your manuscript here: https://www.dovepress.com/cancer-management-and-research-journal 